\title{
The $F T O$ gene is not associated with weight gain during six years of observation in the population of the PURE study in Poland
}

\author{
Aleksandra Zdrojowy-Wełna (101, David Ramsey², Katarzyna Kolačkov ${ }^{\circledR 3}{ }^{3}$, Natalia Słoka ${ }^{(13}$, \\ Katarzyna Zatońska ${ }^{\circledR 4}$, Andrzej Szuba ${ }^{\circledR 5}$, Marek Bolanowski ${ }^{\circledR 1}$ \\ ${ }^{1}$ Department of Endocrinology, Diabetes and Isotope Therapy, Wroclaw Medical University, Wroclaw, Poland \\ ${ }^{2}$ Department of Computer Science and Management, Wroclaw University of Technology, Wroclaw, Poland \\ ${ }^{3}$ Department of Endocrinology, Diabetes and Isotope Therapy, Laboratory of Molecular Endocrinology, Wroclaw Medical University, \\ Wroclaw, Poland \\ ${ }^{4}$ Department of Social Medicine, Wroclaw Medical University, Wroclaw, Poland \\ ${ }^{5}$ Department of Angiology, Hypertension, and Diabetology, Wroclaw Medical University, Wroclaw, Poland
}

\begin{abstract}
Introduction: We present the first longitudinal study in Poland analysing the association between fat mass and obesity-associated gene (FTO) polymorphism and changes in anthropometric parameters.

Material and methods: 1120 participants of the Prospective Urban Rural (PURE) study in Poland (mean age 53.7 years) were genotyped for FTO gene polymorphism (rs9939609, rs9930506, rs1421085, rs1121980). Anthropometric parameters were measured at three time points (baseline, after three years, and after six years of observation).

Results: The mean body mass index (BMI) in the study group was $28 \mathrm{~kg} / \mathrm{m}^{2}$. Overall, there was a significant increase in the mean weight, BMI, and waist size during the six years $(p \approx 0)$. Although males initially weighed more than females $(p=0)$, over the whole six-year period women had a greater tendency to increase in weight $(p=0.068)$, BMI $(p=0.014)$, and waist size $(p=0.041)$. Subjects with at least one A allele at rs9939609 initially weighed more on average $(77.5 v s .74 .7 \mathrm{~kg}, \mathrm{p}=0.027)$ and had a greater waist size $(92 v s .89 .5 \mathrm{~cm}$, $\mathrm{p}=0.025)$ than those with the TT genotype. The differences in baseline results were more expressed in males than in females. There is no association between the changes in anthropometric parameters over the whole study period of six years and the FTO gene.

Conclusions: FTO gene polymorphism is associated with anthropometric parameters in participants from the PURE study in Poland. However, there is no association between the presence of risk alleles and changes of anthropometric parameters over six years of observation. (Endokrynol Pol 2020; 71 (5): 376-381)
\end{abstract}

Key words: FTO gene; polymorphism; obesity; weight gain; longitudinal study

\section{Introduction}

Obesity has become a major health problem worldwide. Globally, the proportion of adults with a body mass index (BMI) of over 25 has risen from $28.8 \%$ to $36.9 \%$ in men and from 29.8 to $38.0 \%$ in women in the years 1980-2013 [1].

Genome-wide association studies (GWAS) have identified many common gene variants associated with obesity. One of them is the fat mass and obesity-associated gene (FTO), located in chromosome region 16q12.2. FTO encodes nucleic acid demethylase, a protein regulating gene expression by the internal modification of messenger RNA (mRNA) [2]. It is highly expressed in regions critical for controlling the energy balance. It has been shown that FTO risk alleles are associated with increased food intake, a preference for high-calorie products and diminished satiety after meals [3-5]. There is also evidence of FTO-specific differences in brain structure and function, as well as in the visual perception of food [6].

The FTO polymorphism is suggested to be the strongest genetic determinant of common obesity [7], also predisposing to extreme obesity [8]. However, this is mostly based on cross-sectional data [7-9]. A few longitudinal studies $[10,11]$ have shown that FTO risk variants predispose individuals to weight gain from childhood until early adulthood, where further weight gain may occur. Most studies suggest that the effect of FTO becomes evident after the age of seven years [10, 12], strengthening throughout childhood up to the age of 20 years, and then weakening with increasing age [13]. 
The frequency of obesity in Poland is rising. According to The Multicentre National Population Health Examination Survey (WOBASZ), the frequency of obesity rose from $22.3 \%$ to $23.4 \%$ in women, and from $20 \%$ to $24.2 \%$ in men, over 10 years of observation [14]. The aim of our study is to evaluate whether the FTO polymorphism is associated with changes in anthropometric parameters over a period of six years of observation based on data from the Prospective Urban Rural Study (PURE) carried out in Poland.

\section{Material and methods}

\section{Study group and examination protocol}

Our analysis was carried out on the basis of data from participants of the PURE Study from Lower Silesia in Poland, whose FTO gene had been sequenced (initially 1120 subjects). During follow-up, 716 participants were observed at three time points (baseline - 2007, after three years, and after six years). The design of the PURE Study has been described previously [15]. Each participant gave oral and written consent. The study was approved by Wroclaw Medical University Ethical Committee (KB 438/2014).

All participants were examined at each time point, including the measurement of height (accuracy of $0.5 \mathrm{~cm}$ ) and weight (accuracy of $0.1 \mathrm{~kg}$ ). On this basis the body mass index (BMI) was calculated:

$$
B M I=\text { weight }(\mathrm{kg}) /[\text { height }(\mathrm{m})]^{2}
$$

Anthropometric measurements included the waist circumference (halfway between the lowest rib and the top of the hipbone) and the hip circumference (at the widest part of the buttocks).

\section{Genotyping}

Each participant was genotyped for four FTO gene variants (rs9939609, rs9930506, rs1421085, and rs1121980). Simultaneous identification of all these single nucleotide polymorphisms (SNPs) was conducted using the mini-sequencing method with a pair of designed specific primers. This method was described precisely in a previous publication [16].

\section{Statistical analysis}

In order to compare the distribution of the genotypes with the Hardy-Weinberg equilibrium, the frequencies of the alleles in the sample were calculated using gene counting, and then the standard chi-squared goodness-of-fit test was used. The $\mathrm{R}^{2}$ measure was used to assess the strength of linkage disequilibrium between two loci, where R is the Pearson coefficient of correlation between the numbers of risk alleles at these loci. Due to the large sample size, the t-test for paired samples was used to test whether the mean BMI or weight had changed over the study period (in the population as a whole and amongst those of a given sex). The t-test for independent samples was used to test whether there existed an association of the initial BMI, initial weight, the change in BMI over the study period, and the change in weight over the study period with sex.

Three models of genetic dominance were used to investigate the relation between genotype and BMI. Model I assumed that the risk allele dominated the non-risk allele. Under this model, the $\mathrm{t}$-test for independent samples was applied to test if the BMI and weight (as well as the changes in these variables) varied according to whether an individual carried at least one risk allele or not. Model II assumed that the non-risk allele dominated the risk allele. Under this model, the t-test for independent samples was applied to test if the BMI and weight (as well as the changes in these variables) varied according to whether an individual carried at least one non-risk allele or not. Model III assumed that there was no dominance relationship between the risk and non-risk alleles. Under this model, analysis of variance was applied to test whether $\mathrm{BMI}$ and weight (as well as the changes in these variables) varied according to the genotype of an individual.

\section{Results}

We collected data from 457 (63.83\%) females and 257 $(36.17 \%)$ males. It is assumed that the missing subjects from the two later sets of observations were missing completely at random, i.e. there was no association between any of the variables and whether individuals were observed at later time points. The mean initial age was 53.7 with a standard deviation of 7.05 and a range between 32 and 74 years.

\section{Comparison with the Hardy-Weinberg equilibrium}

There was no significant deviation from the Hardy-Weinberg equilibrium at any of the four loci (Tab. 1,2).

\section{Analysis of linkage disequilibrium between pairs of loci}

There was very strong linkage disequilibrium between all the studied loci; the minimum $\mathrm{R}^{2}$ value is 0.7681 (Tab. 3). The most common haplotypes (presented in the order rs1121980-rs1421085-rs9930506-rs9939609) are CTAT and TCGA.

Table 1. Comparison with the Hardy-Weinberg equilibrium for FTO polymorphism rs1121980 and rs1421085

\begin{tabular}{|c|c|c|c|c|c|}
\hline \multicolumn{3}{|c|}{ rs1121980 } & \multicolumn{3}{|c|}{ rs1421085 } \\
\hline & Observed & Expected & & Observed & Expected \\
\hline $\mathrm{CC}$ & $215(30 \%)$ & $216.3(30.2 \%)$ & $\mathrm{CC}$ & 142 (19.8\%) & $137.7(19.2 \%)$ \\
\hline CT & 357 (49.9\%) & $354.5(49.5 \%)$ & CT & 344 (48\%) & $352.6(49.2 \%)$ \\
\hline $\mathrm{TT}$ & $144(20.1 \%)$ & $145.3(20.3 \%)$ & TT & $230(32.2 \%)$ & 225.7 (31.6\%) \\
\hline $\mathrm{n}$ & 716 & & $\mathrm{n}$ & 711 & \\
\hline$p$ & 0.85 & & $p$ & 0.51 & \\
\hline
\end{tabular}


Table 2. Comparison with the Hardy-Weinberg equilibrium for FTO polymorphism rs9930506 and rs9939609

\begin{tabular}{cccccc}
\hline & rs9930506 & & \multicolumn{2}{c}{ rs9939609 } \\
\hline & Observed & Expected & & Observed & Expected \\
\hline AA & $207(29.1 \%)$ & $208.5(29.3 \%)$ & AA & $135(19 \%)$ & $131.7(18.5 \%)$ \\
\hline AG & $356(50.1 \%)$ & $353(49.7 \%)$ & $\mathrm{CT}$ & $342(48.1 \%)$ & $348.6(49 \%)$ \\
\hline $\mathrm{GG}$ & $148(20.8 \%)$ & $149.5(21 \%)$ & $\mathrm{TT}$ & $234(32.9 \%)$ & $230.7(32.5 \%)$ \\
\hline $\mathrm{n}$ & 711 & & $\mathrm{n}$ & 711 & \\
\hline $\mathrm{p}$ & 0.82 & & $\mathrm{p}$ & 0.61 & \\
\hline
\end{tabular}

Table 3. Measures of linkage disequilibrium between pairs of loci

\begin{tabular}{llll}
\hline & rs9939609 & rs9930506 & rs1421085 \\
\hline rs1121980 & $\mathrm{R}^{2}=0.8297$ & $\mathrm{R}^{2}=0.8177$ & $\mathrm{R}^{2}=0.9252$ \\
\hline $\mathrm{rs1421085}$ & $\mathrm{R}^{2}=0.8574$ & $\mathrm{R}^{2}=0.7681$ & \\
\hline rs9930506 & $\mathrm{R}^{2}=0.8537$ & & \\
\hline
\end{tabular}

$R$ - Pearson coefficient of correlation; $R^{2}$ - measure of linkage disequilibrium

Table 4. Changes in anthropometric parameters of the participants in the course of the study (standard deviation given in brackets)

\begin{tabular}{|c|c|c|c|}
\hline & Initially & After 3 years & After 6 years \\
\hline \multicolumn{4}{|l|}{ Weight [kg] } \\
\hline Whole group & $76.6(16.1)$ & $76.7(16.3)$ & $77.7(16.6)$ \\
\hline Males & $84.6(15.6)$ & $84.7(15.8)$ & $85.2(15.8)$ \\
\hline Females & $72.0(14.6)$ & $72.2(14.8)$ & $73.4(15.6)$ \\
\hline \multicolumn{4}{|l|}{ BMI $\left[\mathrm{kg} / \mathrm{m}^{2}\right]$} \\
\hline Whole group & $28.0(5.2)$ & $28.1(5.1)$ & $28.5(5.4)$ \\
\hline Males & $28.4(4.7)$ & $28.4(4.6)$ & $28.6(4.6)$ \\
\hline Females & $27.8(5.4)$ & $27.9(5.4)$ & $28.5(5.8)$ \\
\hline \multicolumn{4}{|l|}{ Waist [cm] } \\
\hline Whole group & $91.1(14.0)$ & $91.8(14.1)$ & $93(15)$ \\
\hline Males & $97.2(12.4)$ & $97.7(12.2)$ & $97.9(13.8)$ \\
\hline Females & $87.7(13.7)$ & $88.5(14.0)$ & $90.1(15)$ \\
\hline \multicolumn{4}{|l|}{ Hips [cm] } \\
\hline Whole group & $104(9.9)$ & $102.8(9.8)$ & $103(11.7)$ \\
\hline Males & $102.7(8.7)$ & $102.1(8.9)$ & $101.9(11.2)$ \\
\hline Females & $104.7(10.5)$ & $103.3(10.2)$ & $103.7(11.9)$ \\
\hline
\end{tabular}

Due to this very strong linkage disequilibrium, further analysis was based purely on the genotype at the rs9939609 locus.

\section{Changes in body mass and waist measurements}

The results of anthropometric parameters measurements are presented in Table 4 . The mean BMI in the study group was $28 \mathrm{~kg} / \mathrm{m}^{2}$. Almost $30 \%$ of the participants were obese according to the definition of having BMI over $30 \mathrm{~kg} / \mathrm{m}^{2}$ (208 out of 716). There was no association between sex and obesity. 291 out of 716 participants (40.6\%) were classified as being overweight (BMI $25-29.9 \mathrm{~kg} / \mathrm{m}^{2}$ ). Males were significantly more likely than females to be classified as overweight (123 out of 257 males, $47.9 \%$, and 168 out of 457 females, 36.8\%, $\mathrm{p}=0.004$ ). Close to $40 \%$ of the participants (284 out of 716) were classified as obese on the basis of the waist circumference criterion (over $88 \mathrm{~cm}$ in females and 102 
$\mathrm{cm}$ in males). Females were more likely to be classified as obese according to this criterion (208 out of 457 females, $45.5 \%$, and 76 out of 257 males, $29.6 \%, p=0.00003$ ).

Overall, there was a significant increase in the mean weight and BMI over the full period of six years $(\mathrm{t}=4.95, \mathrm{p} \approx 0$ and $\mathrm{t}=5.70, \mathrm{p} \approx 0$, respectively). There was a significant increase in waist size (both in the course of three years and in the course of six years, $\mathrm{t}=3.12, \mathrm{p}=0.0018$ and $\mathrm{t}=6.21, \mathrm{p} \approx 0$, respectively). There was a significant decrease in hip size (both in the course of three years and in the course of six years, $\mathrm{t}=6.35, \mathrm{p} \approx 0$ and $\mathrm{t}=3.04, \mathrm{p}=0.0025$, respectively). Although males initially weighed more than females $(t=10.61, p=0)$, over the whole six-year period women showed a greater tendency to increase in weight $(\mathrm{p}=0.068)$, BMI $(\mathrm{p}=0.014)$, and waist size $(\mathrm{p}=0.041)$. The fall in hip size over the first three years is greater among females than among males $(\mathrm{p}=0.035)$.

\section{The FTO polymorphism and anthropometric parameters}

The mean change in the anthropometric parameters according to FTO polymorphism are presented in Table 5.

Subjects with at least one A allele at rs9939609 initially weighed more on average than those with the TT genotype (77.5 vs. $74.7 \mathrm{~kg}, \mathrm{p}=0.027)$, although the analogous difference between mean BMIs was not significant (28.3 vs. 27.5, $\mathrm{p}=0.069$ ).
Those with at least one A allele at rs9939609 initially had a greater waist size than those with the TT genotype (92 cm vs. $89.5 \mathrm{~cm}, \mathrm{p}=0.025$ ).

Those with at least one A allele at rs9939609 initially had a greater hip size than those with the TT genotype (104.5 vs. $102.8 \mathrm{~cm}, \mathrm{p}=0.030$ ).

The anthropometric parameters were also analysed for males and females separately. Males with at least one A allele weighed more (85.9 vs. 81.6, $\mathrm{p}=0.022$ ) and had a higher average BMI (28.8 vs. $27.4, \mathrm{p}=0.015)$ initially than those with genotype TT, while there was no association between the FTO genotype and body parameters among females.

There was no association between the changes in weight or BMI over the whole study period of six years and the genotype at FTO rs9939609 based on a model that assumes no dominance relation between the alleles ( $p=0.424, p=0.46$, respectively). There was also no association between the changes in waist or hip size over the whole study period and the FTO polymorphism ( $p=0.565, p=0.718$, respectively). Similar results were obtained on the basis of models that assumed one of the alleles dominated the other.

\section{Discussion}

In this study, we analysed the association between variants of the FTO gene and changes in anthropometric parameters in a group of 716 subjects from the PURE

Table 5. Changes in anthropometric parameters according to the FTO polymorphism (standard deviation given in brackets)

\begin{tabular}{|c|c|c|c|}
\hline & Initially & After 3 years & After 6 years \\
\hline \multicolumn{4}{|c|}{ Weight [kg] } \\
\hline$A A$ & $77.2(16.5)$ & $77.9(17.4)$ & 78.4 (17.7) \\
\hline AT & $77.6(16.8)$ & $77.6(16.7)$ & $78.4(17.0)$ \\
\hline TT & $74.7(14.7)$ & $74.9(15.0)$ & $76.2(15.4)$ \\
\hline \multicolumn{4}{|c|}{ BMI $\left[\mathrm{kg} / \mathrm{m}^{2}\right]$} \\
\hline AA & $28.3(5.6)$ & $28.6(5.7)$ & $28.9(6.0)$ \\
\hline AT & $28.2(5.1)$ & $28.2(4.9)$ & $28.6(5.2)$ \\
\hline TT & $27.5(5.0)$ & $27.5(5.1)$ & $28.2(5.2)$ \\
\hline \multicolumn{4}{|c|}{ Waist [cm] } \\
\hline$A A$ & $92.1(15.4)$ & $93.7(16.2)$ & $94.1(16.4)$ \\
\hline AT & $91.9(13.8)$ & $92.4(13.6)$ & $93.3(15.1)$ \\
\hline TT & $89.5(13.5)$ & $89.9(13.3)$ & $91.7(14.2)$ \\
\hline \multicolumn{4}{|c|}{ Hip [cm] } \\
\hline AA & $104.8(10.3)$ & $104.4(10.5)$ & $104.3(11.6)$ \\
\hline AT & $104.4(9.9)$ & $103.1(9.5)$ & $103.3(11.5)$ \\
\hline TT & $102.8(9.7)$ & $101.6(9.6)$ & $101.9(11.9)$ \\
\hline
\end{tabular}

$\mathrm{BMI}$ - body mass index 
study in Poland over a study period of six years. We examined four FTO polymorphisms (rs9939609, rs9930506, rs1421085, rs1121980) and found very strong linkage disequilibrium between all these loci. This is in accordance with the findings of Sobalska-Kwapis et al., who genotyped 5418 Polish adults and found that rs9939609 was in very high linkage disequilibrium with all the SNPs in block 8 and with a number of SNPs from blocks 3 to 7 [17]. Therefore, our further analysis was based on loci rs9939609.

It was found that the most common haplotypes (given in the order rs1121980- rs1421085- rs9930506rs9939609) were CTAT (all protective alleles) and TCGA (all risk alleles) - so-called "yin-yang" haplotypes. These haplotypes comprised over $90 \%$ of FTO variants in a more homogenous Polish cohort (854 non-obese individuals) that had been genotyped previously [16]. Together with our current results, this confirms that the Polish population is genetically rather homogenous and characterised by two disparate FTO haplotypes with strong linkage disequilibrium between the FTO loci in intron 1.

The mean initial BMI in our group $(28 \mathrm{~kg} / \mathrm{m} 2)$ was indicative that a large proportion of the sample were overweight, and we also observed a high initial mean waist size $(91.1 \mathrm{~cm})$. Both of these parameters increased significantly during the six years of follow-up $(p \approx 0)$. This is in accordance with the global trend of an increasing frequency of obesity [1] and with other Polish studies. During 10 years of observation, the distribution of BMI in the Polish WOBASZ population shifted to higher values, particularly in men [14]. However, in our group, women showed a more significant increase in BMI and waist circumference in comparison to men. This difference remains unclear. The determinants of obesity in our baseline cohort have been previously analysed [18]. It was found that environmental and socioeconomic factors, such as rural inhabitancy, unemployment, and stress, were significantly associated with obesity, especially in women, while genetic factors played a more important role in males. Probably, the environmental determinants of obesity become stronger with time, while genetic predisposition to obesity becomes weaker in older age. Another reason for the greater weight gain in women might be hormonal status. The mean age of females in our group ( 54.3 years) is often associated with hormonal changes due to menopause. Decreases in the oestrogen level may predispose women to fat accumulation in this period. A significant decrease in hip size was observed in our study, greater amongst females than amongst males. Together with an increase in waist size, this is typical of a change from gynoid to android obesity. Such changes are characteristic during the menopausal period, due to decreasing levels of oestrogen.
Few longitudinal studies have analysed the association between the FTO genotype and weight gain. This influence was first discovered in children, where FTO-mediated predisposition to obesity becomes stronger between the ages 4 and 11 years [19]. In a cohort of 1629 Danish men, Jess et al. found that carriers of risk allele were predisposed to weight gain in two periods: from birth to seven years of age and later from adolescence to early adulthood. The mean weight excess in risk allele homozygotes was estimated at $7 \mathrm{~kg}$ at the age of 20 years and $18 \mathrm{~kg}$ at the age of 46 years, compared to non-risk allele homozygotes [10]. However, the assessment of males alone appears to be an important limitation of this study. Similarly, in adolescents from the HUNT study, the FTO polymorphism was associated with becoming overweight in adulthood [11]. In another longitudinal study, Hardy et al. reported that the association between the FTO gene and BMI strengthened from childhood to adolescence, reached its maximal influence at the age of 20 years, and weakened during later life (observations were made up to the age of 53 years) [13]. Qi et al. also stated that the influence of FTO is weaker in older age [20]. We found that the FTO polymorphism is associated with initial weight, BMI, and waist and hip size. This influence is stronger in males - men with at least one A allele on average weigh more ( 85.9 vs. $81.6, \mathrm{p}=0.022)$ and have higher BMI (28.8 vs. 27.4, $\mathrm{p}=0.015)$ initially than those with genotype TT. No such associations were found in females. The reasons for these sex-dependent differences in the influence of FTO on body mass parameters are discussed in our other publication [21]. However, the current study indicates that FTO risk alleles have no significant influence on weight gain in our study group over the six-year study period. Probably, the older age of our participants, in comparison to the aforementioned studies, blurs the effect of genetic predisposition to obesity. We suppose that environmental factors play a greater role in weight gain within this age group. Another possible reason for this negative result might be the relatively short period of observation.

To our knowledge, this is the first longitudinal study in Poland analysing the association between the FTO gene and changes in anthropometric parameters. Previously, Polish studies had only a cross-sectional character. Recently, in a group of 5418 Polish adults it was found that FTO variation was related to BMI. Similarly to our results, the FTO gene predisposes only males to becoming overweight [17]. Other Polish studies were based on smaller groups of subjects.

We believe that it is important to report negative results, because they create a full picture of the problem studied. Our study has some limitations. Of the initial 1120 subjects, 711 were observed during follow-up (both 
after three years and after six years). However, due to the relatively young age of the majority of these participants, it seems to be a reasonable assumption that those subjects who were not observed during follow-up were missing completely at random, and the number of participants remains large. Another strength of this study was that anthropometric and clinical measurements were carried by trained personnel, thus avoiding the pitfall of underor mis-reporting weight-related measures.

\section{Conclusions}

In conclusion, we have found that the FTO gene polymorphism is associated with body mass in males from the PURE study in Poland. However, there is no association between the presence of risk alleles and weight change over six years.

\section{Declaration of interest}

Each author declares that there is no conflict of interest that could be perceived as prejudicing the impartiality of the research reported.

\section{Funding}

This work was supported by the Wroclaw Medical University Grant for Young Researchers (Grant No. 158).

\section{References}

1. Ng M, Fleming $\mathrm{T}$, Robinson $\mathrm{M}$, et al. Global, regional, and national prevalence of overweight and obesity in children and adults during 1980-2013 a systematic analysis for the Global Burden of Disease Study 2013. Lancet. 2014; 384(9945): 766-781, doi: 10.1016/S0140-6736(14)60460-8, indexed in Pubmed: 24880830.

2. Zhao Xu, Yang Y, Sun BF, et al. FTO-dependent demethylation of N6-methyladenosine regulates mRNA splicing and is required for adipogenesis. Cell Res. 2014; 24(12): 1403-1419, doi: 10.1038/cr.2014.151, indexed in Pubmed: 25412662.

3. Ranzenhofer LM, Mayer LES, Davis HA et al. The FTO Gene and Measured Food Intake in 5- to 10-Year-Old Children Without Obesity Obesity (Silver Spring). 2019; 27(6): 1023-1029, doi: 10.1002/oby.22464 indexed in Pubmed: 31119882.

4. Tanofsky-Kraff M, Han JC, Anandalingam K, et al. The FTO gene rs9939609 obesity-risk allele and loss of control over eating. Am J Clin Nutr. 2009; 90(6): 1483-1488, doi: 10.3945/ajcn.2009.28439, indexed in Pubmed: 19828706.

5. Karra E, O'Daly OG, Choudhury AI, et al. A link between FTO, ghrelin and impaired brain food-cue responsivity. J Clin Invest. 2013; 123(8): 3539-3551, doi: 10.1172/JCI44403, indexed in Pubmed: 23867619

6. Kühn AB, Feis DL, Schilbach L, et al. FTO gene variant modulates the neural correlates of visual food perception. Neuroimage. 2016; 128
21-31, doi: 10.1016/j.neuroimage.2015.12.049, indexed in Pubmed: 26767945.

7. Dina C, Meyre D, Gallina S, et al. Variation in FTO contributes to childhood obesity and severe adult obesity. Nat Genet. 2007; 39(6): 724-726, doi: 10.1038/ng2048, indexed in Pubmed: 17496892.

8. Fonseca AC, Marchesini B, Zembrzuski VM, et al. Genetic variants in the fat mass and obesity-associated (FTO) gene confer risk for extreme obesity and modulate adiposity in a Brazilian population. Genet Mol Biol. 2020; 43(1): e20180264, doi: 10.1590/1678-4685-GMB-2018-0264, indexed in Pubmed: 32154826.

9. Chang YC, Liu PH, Lee WJ, et al. Common variation in the fat mass and obesity-associated (FTO) gene confers risk of obesity and modulates BMI in the Chinese population. Diabetes. 2008; 57(8): 2245-2252, doi: 10.2337/db08-0377, indexed in Pubmed: 18487448.

10. Jess T, Zimmermann E, Kring SII, et al. Impact on weight dynamics and general growth of the common FTO rs9939609: a longitudinal Danish cohort study. Int J Obes (Lond). 2008; 32(9): 1388-1394, doi: 10.1038/ijo.2008.110, indexed in Pubmed: 18663371.

11. Kvaløy K, Holmen J, Hveem K, et al. Genetic Effects on Longitudina Changes from Healthy to Adverse Weight and Metabolic Status - The HUNT Study. PLoS One. 2015; 10(10): e0139632, doi: 10.1371/journal. pone.0139632, indexed in Pubmed: 26445370.

12. Hakanen M, Raitakari OT, Lehtimäki T, et al. FTO genotype is associated with body mass index after the age of seven years but not with energy intake or leisure-time physical activity. J Clin Endocrinol Metab. 2009; 94(4): 1281-1287, doi: 10.1210/jc.2008-1199, indexed in Pubmed: 19158205.

13. Hardy R, Wills AK, Wong A, et al. Life course variations in the associations between FTO and MC4R gene variants and body size. Hum Mol Genet. 2010; 19(3): 545-552, doi: 10.1093/hmg/ddp504, indexed in Pubmed: 19880856.

14. Stepaniak U, Micek A, Waśkiewicz A, et al. Prevalence of general and abdominal obesity and overweight among adults in Poland. Results of the WOBASZ II study (2013-2014) and comparison with the WOBASZ study (2003-2005). Pol Arch Med Wewn. 2016; 126(9): 662-671, doi: 10.20452/pamw.3499, indexed in Pubmed: 27535012

15. Teo K, Chow CK, Vaz M, et al. PURE Investigators-Writing Group. The Prospective Urban Rural Epidemiology (PURE) study: examining the impact of societal influences on chronic noncommunicable diseases in low-, middle-, and high-income countries. Am Heart J. 2009; 158(1): 1-7. e1, doi: 10.1016/j.ahj.2009.04.019, indexed in Pubmed: 19540385.

16. Kolačkov K, Łaczmański Ł, Lwow F, et al. The Frequencies of Haplotypes of FTO Gene Variants and Their Association with the Distribution of Body Fat in Non-Obese Poles. Adv Clin Exp Med. 2016; 25(1): 33-42, doi: 10.17219/acem/60645, indexed in Pubmed: 26935496.

17. Sobalska-Kwapis M, Suchanecka A, Słomka M, et al. Genetic association of FTO/IRX region with obesity and overweight in the Polish population. PLoS One. 2017; 12(6): e0180295, doi: 10.1371/journal.pone.0180295, indexed in Pubmed: 28662178

18. Zdrojowy-Wełna A, Zatońska K, Bednarek-Tupikowska G, et al. Determinants of obesity in population of PURE study from Lower Silesia. Endokrynol Pol. 2018; 69(6): 644-652, doi: 10.5603/EP.a2018.0061, indexed in Pubmed: 30229555.

19. Haworth CMA, Carnell S, Meaburn EL, et al. Increasing heritability of BMI and stronger associations with the FTO gene over childhood. Obesity (Silver Spring). 2008; 16(12): 2663-2668, doi: 10.1038/oby.2008.434, indexed in Pubmed: 18846049.

20. Qi Lu, Kang K, Zhang C, et al. Fat mass-and obesity-associated (FTO) gene variant is associated with obesity: longitudinal analyses in two cohort studies and functional test. Diabetes. 2008; 57(11): 3145-3151, doi: $10.2337 / \mathrm{db} 08-0006$, indexed in Pubmed: 18647953.

21. Zdrojowy-Wełna A, Bednarek-Tupikowska G, Zatońska K, et al. The association between FTO gene polymorphism rs9939609 and obesity is sex-specific in the population of PURE study in Poland. Adv Clin Exp Med. 2020; 29(1): 25-32, doi: 10.17219/acem/111811, indexed in Pubmed: 31967745 . 